\title{
RESEARCH
}

\section{Non-canonical AR activity facilitates endocrine resistance in breast cancer}

\author{
KeeMing Chia1,2, Heloisa Milioli1,2, Neil Portman1,2, Geraldine Laven-Law33, Rhiannon Coulson 1,2, Aliza Yong1,2, \\ Davendra Segara², Andrew Parker2, Catherine E Caldon 1,2, Niantao Deng ${ }^{1,2}$, Alexander Swarbrick ${ }^{1,2}$, Wayne D Tilley³, \\ Theresa E Hickey ${ }^{3}$ and Elgene Lim ${ }^{1,2}$
}

1 Garvan Institute of Medical Research, Darlinghurst, New South Wales, Australia

2St Vincent's Clinical School, Faculty of Medicine, UNSW Sydney, Darlinghurst, New South Wales, Australia

${ }^{3}$ Dame Roma Mitchell Cancer Research Laboratories, Adelaide Medical School, University of Adelaide, Adelaide, South Australia, Australia

Correspondence should be addressed to T E Hickey or E Lim: theresa.hickey@adelaide.edu.au or e.lim@garvan.org.au

\begin{abstract}
The role of androgen receptor (AR) in endocrine-resistant breast cancer is controversial and clinical trials targeting AR with an AR antagonist (e.g., enzalutamide) have been initiated. Here, we investigated the consequence of AR antagonism using in vitro and in vivo models of endocrine resistance. AR antagonism in MCF7-derived tamoxifen-resistant (TamR) and long-term estrogen-deprived breast cancer cell lines were achieved using siRNA-mediated knockdown or pharmacological inhibition with enzalutamide. The efficacy of enzalutamide was further assessed in vivo in an estrogen-independent endocrineresistant patient-derived xenograft (PDX) model. Knockdown of AR inhibited the growth of the endocrine-resistant cell line models. Microarray gene expression profiling of the TamR cells following AR knockdown revealed perturbations in proliferative signaling pathways upregulated in endocrine resistance. AR loss also increased some canonical ER signaling events and restored sensitivity of TamR cells to tamoxifen. In contrast, enzalutamide did not recapitulate the effect of AR knockdown in vitro, even though it inhibited canonical AR signaling, which suggests that it is the non-canonical AR activity that facilitated endocrine resistance. Enzalutamide had demonstrable efficacy in inhibiting AR activity in vivo but did not affect the growth of the endocrine-resistant PDX model. Our findings implicate non-canonical AR activity in facilitating an endocrine-resistant phenotype in breast cancer. Unlike canonical AR signaling which is inhibited by enzalutamide, non-canonical AR activity is not effectively antagonized by enzalutamide, and this has important implications in the design of future AR-targeted clinical trials in endocrine-resistant breast cancer.
\end{abstract}

Key Words
- endocrine resistance
- breast cancer
- AR
- enzalutamide
- PDX

\section{Introduction}

The androgen receptor (AR) is a steroid hormone receptor that is important in the development of male-specific phenotype. AR has a well-established canonical function as a ligand-activated transcription factor involved in the regulation of target genes, but it also possesses non-canonical functions via the activation of cytoplasmic signaling cascades. These include the mitogen-activated protein kinase (MAPK) and phosphoinositide-3-kinase (PI3K)/Akt pathways (Zarif \& Miranti 2016). AR signaling plays a critical role in the progression of prostate cancer (c) 2019 Society for Endocrinology Published by Bioscientifica Ltd. Printed in Great Britain 
and inhibitors of AR are a mainstay for treating advanced stages of this disease. These anti-androgenic therapeutic agents may have broader clinical utility, as AR signaling has been implicated in the pathogenesis of other malignancies such as ovarian teratocarcinoma (Chung et al. 2014) and some subtypes of breast cancer (Hickey et al. 2012, Chia et al. 2015).

Breast cancer is a highly heterogeneous disease comprising several major immunohistochemical subtypes. About $70 \%$ of all cases are classified as estrogen receptor positive (ER+) and the remaining 30\% estrogen receptor negative (ER-) breast cancers are sub-classified into two broad categories: HER2-enriched subtype that is human epidermal growth factor receptor 2 positive (HER2+) and triple-negative breast cancer (TNBC), which lacks expression of all three biomarkers (ER, progesterone receptor (PR) and HER2). AR is expressed across all subtypes of breast cancer and approximately 90\% of ER+ (Niemeier et al. 2010), 60-75\% of HER2+ (Micello et al. 2010, Niemeier et al. 2010) and 10-36\% of TNBC (Micello et al. 2010, Niemeier et al. 2010) are immunopositive for AR.

The consequences of AR activity are subtype dependent. In the ER+ breast cancer, multiple in vitro studies have reported a growth inhibitory effect of 5 alpha-dihydrotestosterone (DHT), the most potent cognate ligand for $\mathrm{AR}$, in endocrine-sensitive $\mathrm{ER}+\mathrm{AR}+$ cell line models of breast cancer (Lapointe et al. 1999, Greeve et al. 2004, Macedo et al. 2006), and this effect is reported to be mediated via antagonism of ER signaling (Lapointe et al. 1999, Lanzino et al. 2005, Macedo et al. 2006, Peters et al. 2009). These studies suggest that AR activity is tumor suppressive in ER+ breast cancer, a concept supported by clinical studies showing that AR expression is an independent prognostic marker of good outcome in ER+ breast cancers (Aleskandarany et al. 2016, Ricciardelli et al. 2018). In contrast, AR activity is associated with increased proliferation in the ER- breast cancer (Chia et al. 2011, Lehmann et al. 2011, Ni et al. 2011, Robinson et al. 2011)

Standard-of-care endocrine therapy for ER+ breast cancer includes selective ER modulators such as tamoxifen, aromatase inhibitors (AIs) that inhibit peripheral estrogen biosynthesis and selective ER degraders (SERDs) such as fulvestrant. While endocrine therapies have improved the survival of patients with early-stage ER+ disease, approximately one-third of women will eventually acquire resistance to endocrine therapy, leading to disease progression and death (EBCTCG 2005). The expression of $\mathrm{AR}$ is reported to be higher in endocrine-resistant breast cancer, but the role of AR in these tumors is controversial (De Amicis et al. 2010, Fujii et al. 2014).

AR activity has been reported to promote proliferation as growth suppression of endocrine-resistant cells was observed with the use of AR inhibitors such as bicalutamide and enzalutamide (De Amicis et al. 2010, Rechoum et al. 2014, Ali et al. 2015, Ciupek et al. 2015, D'Amato et al. 2016). These preclinical studies have contributed to the initiation of clinical trials with AR inhibitors including enzalutamide in endocrine-resistant breast cancer (ClinicalTrials.gov NCT Identifiers 02953860, $02007512 \& 02580448)$. However, it is noteworthy that these studies largely utilized genetically modified MCF7 cell line models of endocrine resistance, which includes ectopic overexpression of AR (De Amicis et al. 2010) or knockdown of Rho GDP dissociation inhibitor (GDI) (Ciupek et al. 2015) in MCF7 cells to mimic tamoxifen resistance. MCF7 cells with ectopic overexpression of aromatase with or without ectopic AR overexpression were used as models of aromatase inhibitor resistance (Rechoum et al. 2014, Ali et al. 2015). There is only one study utilizing non-genetically modified cell line models of endocrine resistance, which demonstrated that enzalutamide inhibited in vitro and in vivo growth of tamoxifen-resistant (TamR) MCF7 cells (D'Amato et al. 2016). Critically, the effect of AR antagonism on an endocrine-resistant patient-derived xenograft (PDX), now considered the most clinically relevant preclinical disease model, is yet to be reported.

Here, we examined the consequences of antagonizing endogenous AR in breast cancer cell lines using siRNAmediated knockdown or AR antagonist enzalutamide and investigated the effect of enzalutamide in a PDX model of endocrine resistance. We demonstrate that AR plays a functional role in endocrine-resistant breast cancer as knockdown of $\mathrm{AR}$ reversed the endocrine-resistant phenotype. This functional role of AR is, however, ascribed to its non-canonical activity, which was not inhibited by enzalutamide as the growth of cell line and PDX models was unaffected by the drug. These observations suggest that pharmacologically inhibiting AR may not be an effective therapeutic strategy for endocrine-resistant breast cancer.

\section{Materials and methods}

\section{Cell culture and reagents}

MCF7 cells were sourced from the Michigan Cancer Foundation. Derivatives of MCF7 cells that are resistant 
to tamoxifen (TamR) or long-term estrogen deprived (LTED) were obtained from Myles Brown (Dana-Farber Cancer Institute) (Bailey et al. 2015). T47D cells were obtained from the American Type Culture Collection. All cell lines have been verified through short tandem repeat profiling, and mycoplasma contamination was excluded. MCF7, TamR and T47D cell lines were cultured in RPMI 1640 media (Thermo Fisher) supplemented with $10 \%$ fetal bovine serum (GE Healthcare), $20 \mathrm{mM}$ HEPES (Thermo Fisher) and $0.28 \mathrm{IU} / \mathrm{mL}$ insulin (Novo Nordisk). Base media for TamR cells was also supplemented with $5 \mu \mathrm{M}$ 4-hydroxytamoxifen (Sigma). TamR cells used in experiments were grown in base media without tamoxifen. The LTED cell line was maintained in phenolred free RPMI 1640 media (Thermo Fisher) supplemented with 10\% steroid-depleted FBS (Thermo Fisher), $20 \mathrm{mM}$ HEPES (Thermo Fisher) and $0.28 \mathrm{IU} / \mathrm{mL}$ insulin (Novo Nordisk). All cells were cultured in a humidified incubator at $37^{\circ} \mathrm{C}$ with $5 \% \mathrm{CO}_{2}$ and were used at $<10$ passages post revival. The AR antagonist enzalutamide (Selleck) was re-suspended as a $40 \mathrm{mM}$ stock solution in DMSO and DHT (Sigma) was re-suspended as a $10 \mu \mathrm{M}$ stock solution in ethanol.

\section{SiRNA knockdown}

Transient AR knockdown was performed using two different siRNA oligos: AR siRNA-A (siA) 5'-GGAACUCGAUCGUAUCAUU-3' (\#4390824, Thermo Fisher) and AR siRNA B (siB) 5'-CAGUCCCACUUGUGUCAAA-3' (Sigma) (Wang et al. 2011). Cells were transfected with nonsense (NS) siRNA (\#4390843, Thermo Fisher) as a control. Transfection of these siRNAs was carried out using Lipofectamine RNAiMAX (Thermo Fisher), via reverse transfection, as per manufacturer's instructions, using a final siRNA concentration of $10 \mathrm{nM}$ in $2 \mathrm{~mL}$ of media in $6 \mathrm{~cm}^{2}$ culture dishes. For downstream proliferation assays, cells were trypsinized and then seeded at the appropriate cell numbers 2 days post transfection.

\section{Western blotting analysis}

Cell pellets were lysed in RIPA buffer supplemented with Halt Protease and Phosphatase Inhibitor Cocktail (Thermo Fisher). Protein lysates $(20 \mu \mathrm{g})$ were resolved by using $4-15 \%$ mini-Protean TGX pre-cast gels (Bio-Rad) and transferred to $0.45 \mu \mathrm{m}$ Immobilon-FL polyvinylidene fluoride membrane (Millipore). Membranes were immunoblotted with primary antibodies from Cell
Signaling at a dilution of 1 in 1000; anti-AR (\#5153), anti-ER (\#8644), anti-PR (\#3153) anti-FOXA1 (\#23738), anti-Akt (total; \#2920), anti-Akt (phospho-serine 473; \#9271), anti-FOXO3a (\#2497) and GAPDH (\#5174), and anti-cyclin A (\#sc-596, 1:200, Santa Cruz). These antibodies were detected using IRDye 680RD Donkey antimouse (\#926-68072, LI-COR) or IRDye 800CW Donkey anti-Rabbit (\#926-32213, LI-COR) secondary antibodies at a dilution of 1 in 20,000 on the Odyssey CLx Imaging System (LI-COR). Densitometric analyses were carried out using ImageJ.

\section{Real-time quantitative PCR (RT-qPCR)}

Total RNA was extracted using the RNeasy Plus Mini kit (Qiagen). RT-qPCR analysis was performed using the TaqMan Gene Expression Assays (Thermo Fisher) on the 7900HT Fast Real-Time PCR System (Thermo Fisher) or the iQ SYBR Green system (Bio-Rad) on the CFX384 Touch cycler (Bio-Rad) as per manufacturers' instructions. TaqMan probes used are as follows: AR (Hs00907244 m1), ESR1 (Hs01046816_m1), CTGF (Hs00170014_m1), CXCL8 (Hs00174103_m1), PGR (Hs01556702_m1) and GAPDH (Hs03929097_g1). Primers used include SEC14L2 (forward: GCCGAATCCAGATGACTATTTTCT, reverse: GATGTTGTCAATGTCCTTTTGCTT), FKBP5 (forward: AAAAGGCCAAGGAGCACAAC, reverse: TTGAGGAGGGGCCGAGTTC) and GAPDH (forward: TGCACCACCAACTGCTTAGC, reverse: GGCATGGACTGTGGTCATGAG). Expression level of the gene of interest was normalized to that of GAPDH. Relative fold change was computed based on the $(2 \Delta \Delta \mathrm{CT})$ method and data are represented as relative to the control treatment group.

\section{Proliferation assays}

Cell proliferation was measured using Countess Automated Cell Counter and AlamarBlue cell viability assays (Thermo Fisher). Overall, 50,000 cells were seeded into $6 \mathrm{~cm}^{2}$ dishes in $2 \mathrm{~mL}$ media and treatment commenced the following day and cells were quantified 4 days post treatment. Experiments were performed in three independent replicates. Cell viability assays were performed according to manufacturer's instructions in 96-well plate format. 2-4000 cells were seeded into each well in $100 \mu \mathrm{L}$ media and treatment commenced the following day. Growth media was replaced with $200 \mu \mathrm{L}$ of fresh media containing $1 \times$ concentration of the indicated treatment every 2-3 days and cells were analyzed 3-6 days 
post treatment. Technical repeats (6-8) were performed for each condition and experiments were performed in three independent replicates.

\section{Colony-forming assays}

Assays were performed in 12-well plates seeded at a density of $\sim 3000$ cells per well. Treatment was added $24 \mathrm{~h}$ later and cells were harvested after 6-9 days of treatment. Cells were stained with $0.05 \% \mathrm{w} / \mathrm{v}$ crystal violet (Sigma), $1 \%$ formaldehyde (Thermo Fisher), $1 \times$ PBS and 1\% methanol in distilled water. Images were scanned using the Perfection V800 Photo Scanner (Epson) with a DPI of 1200 dots per inch. Area occupancy was analyzed using an ImageI plugin, ColonyArea (Guzman et al. 2014), and the results for treatment groups were expressed relative to controls. Experiments were performed in three independent replicates, each comprising three technical replicates for each condition.

\section{ChIP-PCR}

Chromatin immunoprecipitation (ChIP) was performed in TamR cells as previously described (Holmes et al. 2016) using anti-ER (sc-543x) and anti-IgG (sc-2027) (Santa Cruz). ER binding to the distal and proximal CXCL8 gene promoters was assessed by RT-qPCR using iQ SYBR Green Supermix according to manufacturer's instructions (\#1708885, Bio-Rad) (Fu et al. 2016). ER occupancy at the CXCL8 promoter regions was expressed as fold enrichment over IgG, normalized to the intergenic controls and then expressed as fold change relative to the control group.

\section{Immunofluorescent staining}

TamR cells grown on poly-L-lysine-coated coverslips were treated with vehicle or $10 \mu \mathrm{M}$ enzalutamide for $48 \mathrm{~h}$ in the absence or presence of $10 \mathrm{nM}$ DHT. Coverslips were fixed in ice-cold methanol overnight at $-20^{\circ} \mathrm{C}$. Cells were immunostained with primary antibodies against AR (\#5153, Cell Signaling), ER (\#M7047, DAKO) and alpha-tubulin (\#T6199, Sigma). Fluorescent secondary antibodies were used to detect the primary antibodies (1:250) and DNA was counterstained with 4,6-diamidino2-phenylindole (1:250, DAPI, Sigma). Coverslips were mounted onto glass slides with Prolong Gold anti-fade reagent (Thermo Fisher) and microscopy was carried out using Automated Upright Microscope System (Leica). DAPI staining was used to define nuclear regions and fluorescent nuclear ER signals were quantified to assess changes in nuclear ER in the different conditions.

\section{Microarray and gene set enrichment analysis}

Gene expression profiling was performed on the TamR cells $48 \mathrm{~h}$ post transfection with NS control or AR siRNA-A using three biological replicates. Microarray hybridization was performed on the Affymetrix PrimeView Human Gene Expression Array. CEL files were further processed in the R software ( $\mathrm{v}$ 3.4.3) environment using affy (Gautier et al. 2004) and limma (Ritchie et al. 2015) packages from Bioconductor (Gentleman et al. 2004). The CEL files and normalized expression matrix can be downloaded from Gene Expression Omnibus (GEO, accession number 115270). Normalized $\log 2$ probe signals were computed using robust multi-array average (RMA) (Irizarry et al. 2003). The subsequent differential expression vectors between AR-knockdown and control samples were set for each gene at a $q$-value threshold of 0.05. Probes were then annotated using the Affymetrix Archived NetAffx Annotation Files for PrimeView. Differentially expressed genes were matched against hallmark signatures from the Molecular Signature Database (MSigDB) using the Gene Set Enrichment Analysis (GSEA) portal (http://software. broadinstitute.org/gsea/index.jsp) (Subramanian et al. 2005) and the degree of overlap between our differentially expressed genes and the signatures were reported.

\section{Endocrine-resistant patient-derived breast cancer xenograft (PDX) model}

PDX (Gar15-13) was generated under the Human Research Ethics Committee (HREC)-approved protocol at the St Vincent's Hospital (SVH) (Protocol HREC/16/SVH/29) and in vivo experiments were approved by the Garvan Animal Ethics Committee (Protocol 15/25). The patient has consented to the use of her tissue for research-related purposes. This PDX was established from a metastatic $\mathrm{ER}+\mathrm{PR}-\mathrm{AR}+$ liver biopsy obtained from a patient with ER+ breast cancer who had disease progression on an aromatase inhibitor. Consistent with its aromatase inhibitorresistant phenotype, this model did not require estradiol supplementation for growth. Patient tumor tissues were implanted into the 4th inguinal mammary gland of female NOD-SCID-IL2 $\gamma \mathrm{R}^{-/-}$(NSG) mice (Australian BioResources) as previously described (Oakes et al. 2012). Animals were anesthetized with isoflurane, and analgesia was achieved with ketoprofen and bupivacaine. The PDX tumor was (c) 2019 Society for Endocrinology Published by Bioscientifica Ltd. Printed in Great Britain 
concordant with the patient tissue (ER+PR-AR+). For the therapeutic experiments, a single PDX tumor was divided and implanted into a cohort of NSG recipient mice. Tumorbearing mice were randomized using the online GraphPad Software to receive either vehicle or enzalutamide when tumors reached 150-200 $\mathrm{mm}^{3}$ (https://www.graphpad. com/quickcalcs/randomize1.cfm). Enzalutamide was re-suspended in 25\% TWEEN ${ }^{\circledR} 80$ (Sigma) and sonicated using Bioruptor (Diagenode) at medium setting for $5 \mathrm{~min}$ at $30 \mathrm{~s}$ on/off intervals to achieve a homogenous suspension and administered at a dose of $20 \mathrm{mg} / \mathrm{kg} /$ day by oral gavage (Moilanen et al. 2015). Tumor volumes were calculated using the formula (length $\times$ wide $\times$ wide) $/ 2$. Mice were culled when the tumors reached ethical endpoint of $1000 \mathrm{~mm}^{3}$.

\section{Immunohistochemistry (IHC) and quantification}

Antibodies used for IHC include anti-AR (\#SC-27190, 1:1000, Santa Cruz), anti-ER (M7047, 1:300, Agilent), anti-Ki67 (M7240, 1:400, Agilent) and anti-SEC14L2 (\#271902, 1:1000, Santa Cruz). These primary antibodies were detected with biotinylated IgG secondary antibodies (Agilent, 1:400), using streptatvidin-HRP (Agilent) for amplification of signal followed by the addition of 3,3'-diaminobenzidine (Sigma) substrate for visualization of signal. Images were scanned using NanoZoomer (Hamamatsu). Proliferation indices were determined by the proportion of Ki- 67 positive cells for each tumor by manual counting of $>1000$ cells from three random $80 \times$ magnification fields (Dowsett et al. 2011). Quantification of staining intensity was performed using ImageJ from at least three representative images at $80 x$.

\section{Statistical analyses}

Statistical analyses were performed on GraphPad Prism version and the type of statistical analysis performed for each experiment is described in the figure legends.

\section{Results}

\section{AR knockdown reduces the proliferation of ER+AR+ endocrine-resistant cells}

We first evaluated possible changes in the expression of steroid hormone receptors and the critical pioneer factor FOXA1 (Hurtado et al. 2011) in the endocrine-resistant cells and western blots were performed to compare ER, AR, $\mathrm{PR}$ and FOXA1 levels in the endocrine-sensitive (ES) MCF7 cells and the endocrine-resistant derivatives (Fig. 1A). ER expression was retained in the endocrine-resistant models and was slightly increased in the TamR cells compared to the ES and LTED cells. AR expression was increased in both endocrine-resistant models relative to ES cells, with higher levels in the LTED model (Fig. 1A). In the TamR line, PR expression was lost and FOXA1 expression increased, consistent with previously published data (Fu et al. 2016).

To assess the effect of AR loss on proliferation of these endocrine-resistant cells, we performed transient knockdown of AR using two specific AR siRNAs (AR siA and siB). Both resulted in reduction of AR transcript and protein levels as demonstrated by RT-qPCR (Supplementary Fig. 1A and B, see section on supplementary data given at the end of this article) and immunoblotting, respectively (Fig. 1B). AR knockdown significantly reduced proliferation of TamR and LTED cells relative to NS siRNA-transfected controls, as determined by cell counting and Alamar Blue viability assays (Fig. 1C, D, E and F). Collectively, these observations support a mitogenic role for AR in endocrine-resistant breast cancer.

\section{AR knockdown restores characteristics of classical ER signaling in MCF7 TamR cells}

We next performed gene expression profiling to identify transcriptomic changes associated with transient knockdown of AR in TamR cells. Efficient AR knockdown was confirmed at both the transcript and protein levels prior to gene expression profiling (Fig. 2A and B). Loss of AR was associated with increased levels of ER protein (Fig. 2B) and immunofluorescence staining indicated an increase in nuclear ER protein in these cells (Supplementary Fig. 2A and B). Notably, AR expression demonstrated a diffuse and predominantly cytoplasmic pattern under the control (NS) conditions (Supplementary Fig. 2A). The predominant cytoplasmic localization of AR and nuclear localization of ER in ES, TamR and LTED cells under basal growth conditions were confirmed via immunoblotting of ER and AR in cytoplasmic and nuclear fractions (Supplementary Fig. 3).

Transcriptional profiling identified 3313 differentially expressed genes at a false discovery rate $<0.05$, with 1605 and 1708 genes upregulated and downregulated respectively. GSEA indicated that genes upregulated by AR knockdown were enriched in pathways involved in ultraviolet response, PI3K-Akt signaling, p53 and estrogen response (Fig. 2C). Conversely, pathways involved in E2F, G2/M checkpoint, androgen response and estrogen (c) 2019 Society for Endocrinology Published by Bioscientifica Ltd. Printed in Great Britain 
A

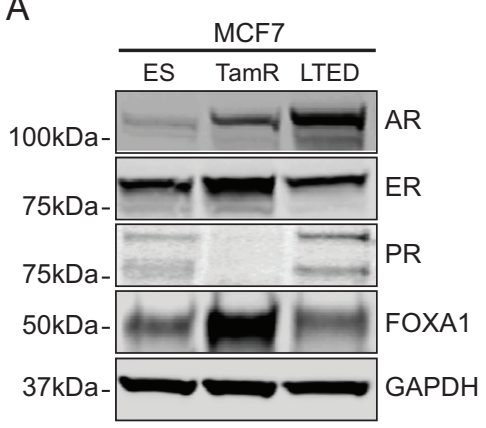

C MCF7 TamR

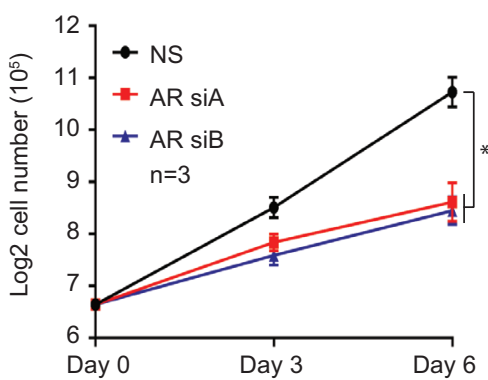

E

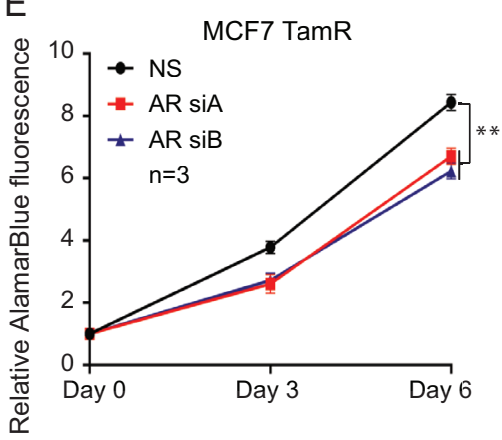

B
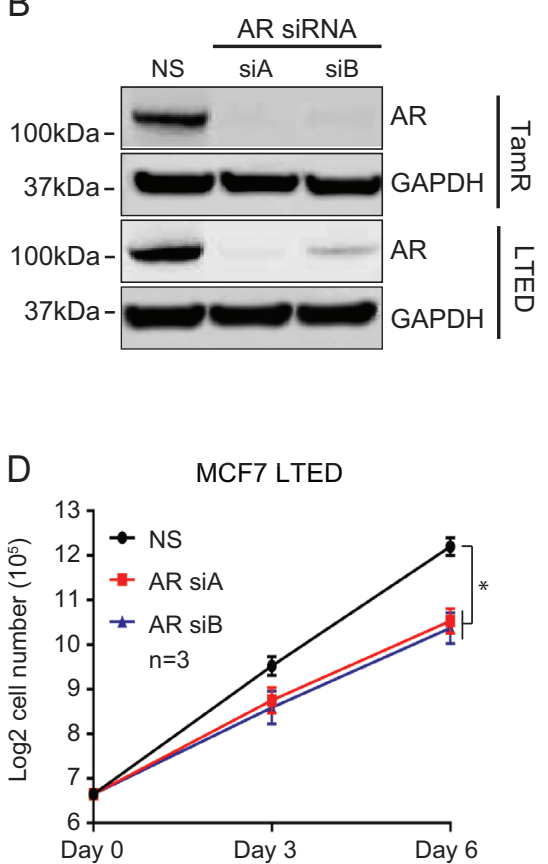

$\mathrm{F}$

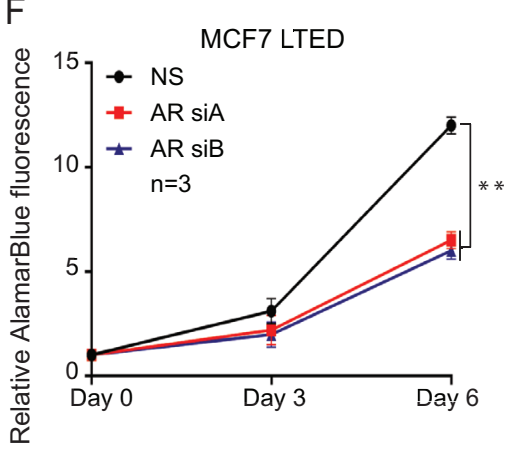

\section{Figure 1}

AR knockdown reduces proliferation of ER+AR+ endocrine-resistant cells. (A) Expression of steroid hormone receptors including AR, ER, PR and FOXA1 in endocrine-sensitive (ES), tamoxifenresistant (TamR) and long-term estrogen-deprived (LTED) MCF7 cell lines by immunoblotting. (B) The efficiency of AR siRNA-A (SiA) and siRNA B (siB) on $A R$ protein in the endocrine-resistant cell lines was compared to nonsense (NS) siRNA 4 days post transfection by immunoblotting for $A R$ and GAPDH (loading control). The effect of AR loss on proliferation was assessed using cell counting and AlamarBlue assay 3 and 6 days post transfection in TamR ( $C$ and $E$ ) and LTED ( $D$ and F) cells. Cell numbers in log2 scale are presented in (C) and (D). ${ }^{*} P<0.05,{ }^{*} * P<0.01$ using Student's $t$-test. Error bars $=$ S.E.M. from three biological replicates. response were enriched in the downregulated gene set (Fig. 2C). A heat map of the top 50 differential genes revealed C-X-C motif chemokine ligand 8 (CXCL8) and connective tissue growth factor $(C T G F)$ as the top two genes downregulated with the loss of cytoplasmic AR (Supplementary Fig. 4). These genes have recently been reported to promote tamoxifen resistance and are highly regulated by ER in MCF7 TamR cells (Fu et al. 2016).

To identify the estrogen response genes affected by AR knockdown, we overlapped the differential gene set with the hallmark Estrogen Response Early gene set (Broad Institute) (Fig. 2D). AR is a component of this hallmark gene set, and was downregulated as expected. Notably, transcript levels of classical ER-regulated genes such as progesterone receptor $(P G R)$, insulin-like growth factor 1 receptor $(I G F 1 R)$ and retinoic acid receptoralpha $(R A R A)$ were increased in AR-deficient TamR cells. This is consistent with the increase in ESR1 mRNA and ER protein levels post AR knockdown (Fig. 2B). Using RT-qPCR, we validated the increases in ESR1 (0.8 log2-fold change, $P<0.01$ ) and $P G R$ mRNA levels (1.8 $\log 2$-fold change, $P<0.05)$, as well as reductions in both CXCL8 ( $-3.35 \log 2$-fold change, $P<0.05)$ and CTGF (-2.7 log2-fold change, $P<0.05)$ mRNA levels post AR knockdown (Fig. 2E). The decrease in CXCL8 transcripts post AR knockdown was associated with a significant reduction ( $50 \%)$ in ER chromatin binding at both the distal and proximal promoter regions (Fig. 2F). Transient AR knockdown in LTED cells also resulted in an increase in ER protein as well as ESR1 and PGR mRNA levels (Supplementary Fig. 5A and B). Collectively, these data suggest that AR in endocrine-resistant MCF7 cells contributes to endocrine-resistant phenotype by inhibiting canonical ER signaling events. This led us to hypothesize that ablation of AR may restore sensitivity to tamoxifen. 
A

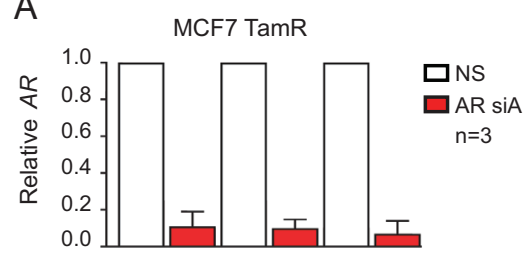

B

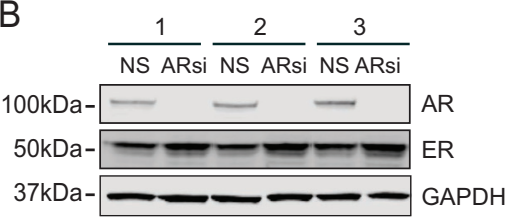

$\mathrm{E}$

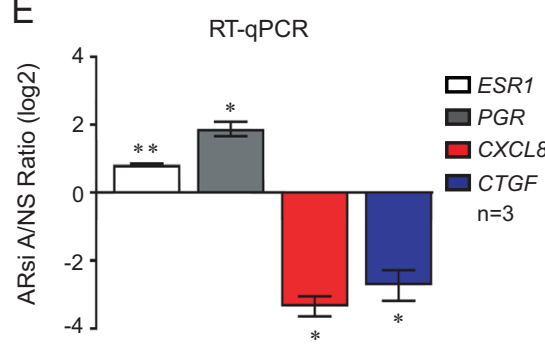

C

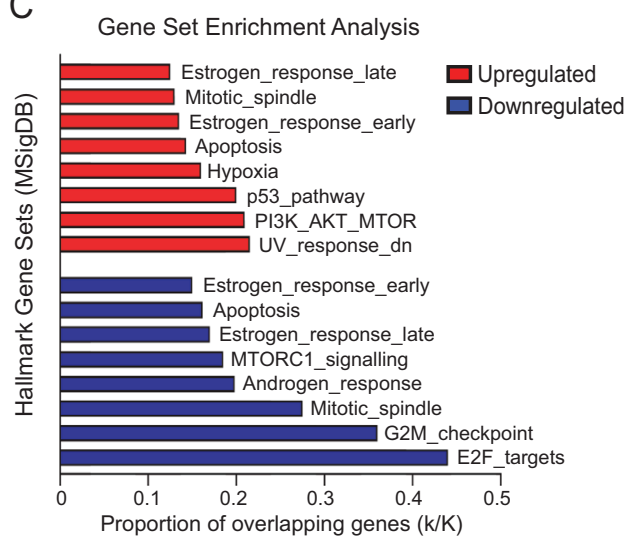

$\mathrm{F}$

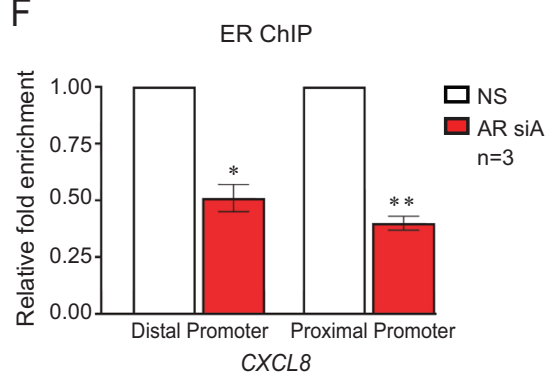

D

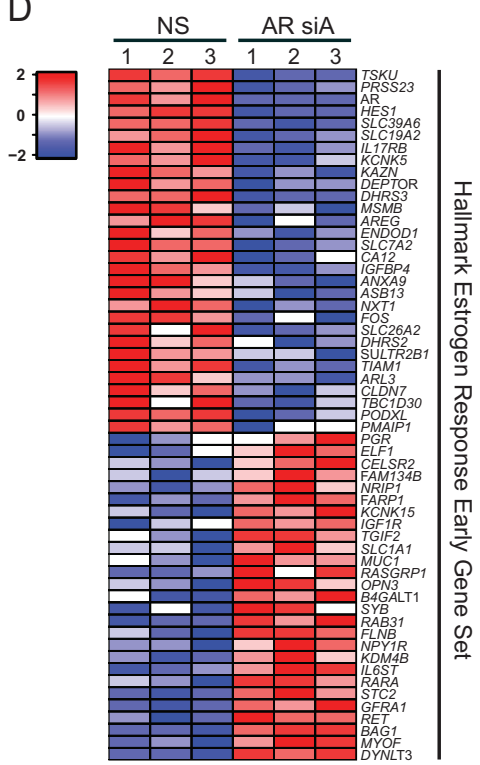

\section{Figure 2}

AR knockdown restores characteristics of classical ER activity. The effect of AR knockdown on gene expression using microarray profiling and on ER chromatin binding at selected sites in MCF7 TamR cells was assessed. The efficiency of AR siA vs that of NS 2 days post transfection was assessed using RT-qPCR (A) and immunoblotting (B). Each reaction was performed in three technical replicates and error bars = S.D. (C) Differentially expressed genes identified from microarray profiling were subjected to MSigDB hallmark GSEA. The top nine enrichment groups for the up- and downregulated genes, with q values of $<0.001$ are presented. (D) The differential gene set induced by the transient knockdown of AR was overlapped with that of the MSigDB hallmark Estrogen Response Early signature. (E) RT-qPCR was used to validate changes in the selected genes ESR1, PGR, CXCL8 and CTGF identified in the expression profiling. Changes in these genes post AR knockdown are presented as log2-fold change of the expression of each gene in AR siRNAtransfected cells relative to NS siRNA-transfected cells. (F) ER binding at distal and proximal CXCL8 promoters post AR knockdown was assessed using chromatin immunoprecipitation (ChIP). Data is represented as fold change relative to NS-transfected cells. * $P<0.05, * \star P<0.01$ using Student's $t$-test. Error bars = S.E.M. from three biological replicates.

\section{AR knockdown restores tamoxifen sensitivity in TamR cells}

Next, we evaluated the effect of tamoxifen on proliferation following AR loss. Tamoxifen increased the viability of NS-transfected cells relative to vehicle controls $(P<0.05$, Fig. 3A), consistent with the mitogenic effect of tamoxifen on MCF7 TamR cells (Jeselsohn et al. 2017). In contrast, tamoxifen significantly reduced viability of AR-deficient cells compared to vehicle treatment $(P<0.05$, Fig. 3A). Colony-forming assays recapitulated these findings, whereby fewer colonies were observed in tamoxifentreated cells following transfection with AR siA- or siB relative to vehicle $(P<0.01$, Fig. $3 \mathrm{~B}$ and $\mathrm{C})$. Tamoxifen did not significantly impact the colony formation of NS-transfected cells. Given that phosphorylation of ER at serine-118 was predictive of response to tamoxifen in early-stage breast cancer (Murphy et al. 2004), we assessed if AR knockdown altered phosphorylation of ER at this site. AR knockdown in TamR cells increased phosphorylation of ER at serine-118, but it occurred proportionately to the observed increase in total ER (Fig. 3D). We then investigated the effect of AR loss on the PI3K/Akt signaling pathway given that it was significantly enriched among genes differentially expressed in the absence of AR (Fig. 2C) and inhibition of this pathway has been shown to augment canonical ER activity and enhance the efficacy of an ER-targeted therapy in ER+ tumors (Bosch et al. 2015). AR knockdown reduced phosphorylation of Akt at serine-473 and increased the expression of downstream Forkhead box transcription factor 3a (FOXO3a), which is negatively regulated by the Akt signaling pathway (Guo \& Sonenshein 2004). These observations suggested that the loss of AR in TamR cells was sufficient to re-sensitize these cells to tamoxifen and that this effect may be attributed to inhibition of the PI3K/Akt signaling pathway. 
A

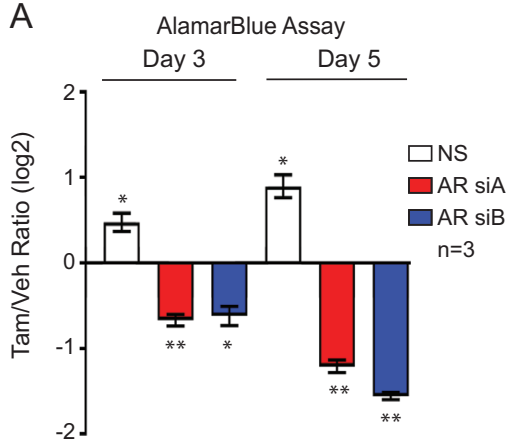

C

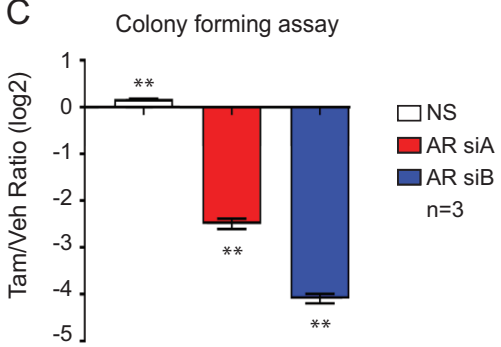

B

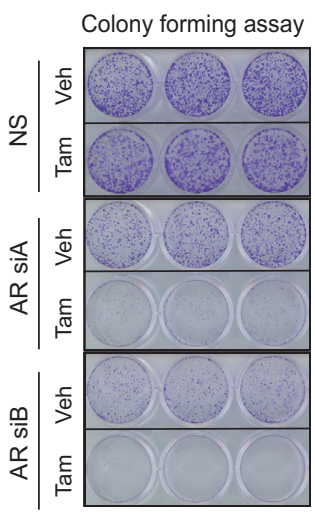

D

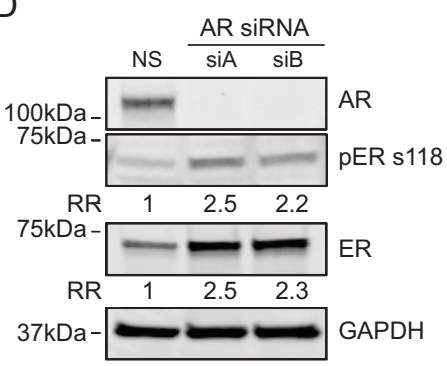

E

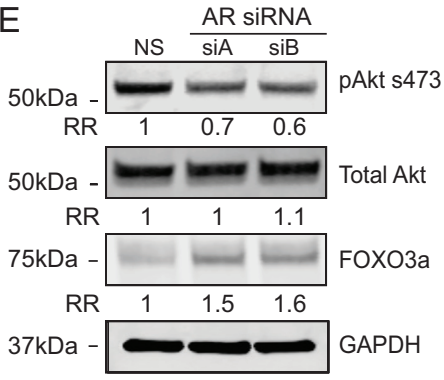

\section{Figure 3}

AR knockdown re-sensitizes MCF7 TamR cells to tamoxifen. The effect of AR knockdown on the response of MCF7 TamR cells to tamoxifen was evaluated using AlamarBlue and colony formation assays. (A) The viability of MCF7 TamR cells was assessed using AlamarBlue assay in response to 3 and 5 days treatment with vehicle (Veh) or $5 \mu \mathrm{M}$ tamoxifen (Tam) after transfection with NS, AR siA or AR siB RNA for 2 days. Data is presented as the fold change of Tam-treated cells to Veh-treated cells in log2 ratio. (B) 6-day colony-forming assay assessing the response of MCF7 TamR to Tam as per the treatment and transfection conditions in (A). (C) Quantification of the colony area coverage using Image with data presented as the fold change of tamoxifen to Veh-treated cells in log2 ratio. (D) Cell lysates extracted from MCF7 TamR cells transfected with NS, AR siA or AR siB for 2 days, were immunoblotted for AR, phospho-ER at serine-118 (pER s118), ER and GAPDH. (E) Cell lysates in (D) were immunoblotted for phospho-Akt at serine 473 (pAKT s473), total Akt, FOXO3a and GAPDH. Densitometry was performed using Image and data is represented relative to control cells (RR; relative ratio). $* P<0.05$, $* \star P<0.01$ using Student's $t$-test. Error bars = s.E.M. from three biological replicates.

\section{Pharmacological inhibition of AR does not phenocopy the effect of AR knockdown}

We then determined if pharmacological inhibition of AR with enzalutamide, which works in part by blocking nuclear localization of ligand-bound AR (Tran et al. 2009), could recapitulate the effect of AR knockdown. We first assessed the effect of enzalutamide, in the presence or absence of DHT, on AR expression and cellular localization. Under basal growth conditions, without DHT supplementation, enzalutamide reduced AR expression by $\sim 14 \%$ relative to vehicle-treated cells (Fig. 4A). As expected, DHT-induced stabilization of AR protein, which increased by 1.8fold relative to vehicle treatment. This DHT-mediated AR stabilization effect was completely abrogated with enzalutamide treatment. The expression of ER was not significantly altered in response to enzalutamide (Fig. 4A). Using immunofluorescence analysis, enzalutamide also inhibited DHT-induced AR nuclear translocation, consistent with its mechanism of action (Fig. 4B).
In contrast to siRNA-mediated loss of AR, functional antagonism with enzalutamide had no effect on the colony formation of TamR cells relative to vehicle treatment (Fig. 4C and D). Similarly, treatment with enzalutamide had no effect on the viability of TamR cells, and it did not re-sensitize TamR cells to the inhibitory effects of tamoxifen (Fig. 4E). In contrast to the effect of transient AR knockdown in these cells (Fig. 2E), enzalutamide increased CTGF (1 log2-fold change, $P<0.05)$, modestly decreased ER $(-0.28 \log 2$-fold change, $P<0.05)$ and CXCL8 levels $(-0.34 \log 2$-fold change, $P<0.05$ ) (Fig. 4F) but had no effect on the expression of $P G R$. Enzalutamide also did not inhibit the PI3K/Akt pathway, as there were no changes observed in the phosphorylation of Akt at serine- 473 or in the expression level of FOXO3a (Fig. 4G). Furthermore, enzalutamide did not reduce the viability of LTED cells, suggesting its lack of efficacy was not limited to one form of endocrine resistance (Fig. 4H). These results demonstrate that pharmacological inhibition of AR does not recapitulate the effect of AR knockdown in endocrine-resistant breast cancer cells in vitro. 
A

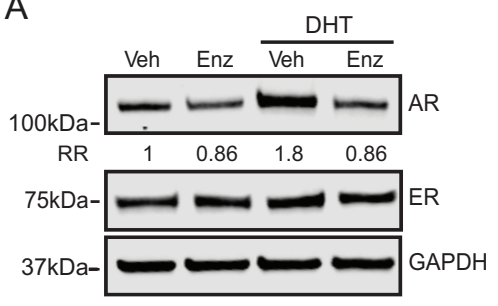

C

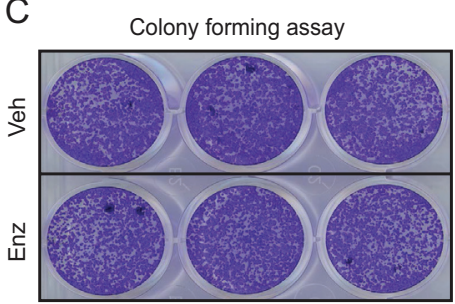

E

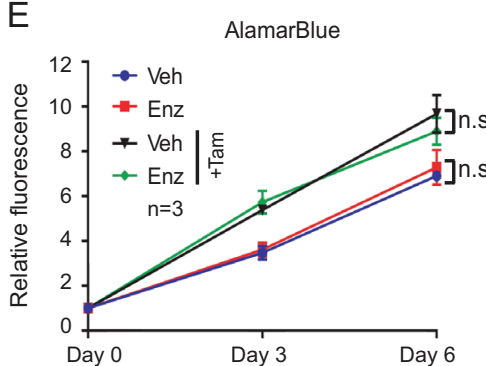

G

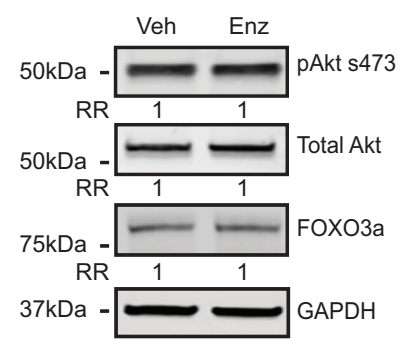

B

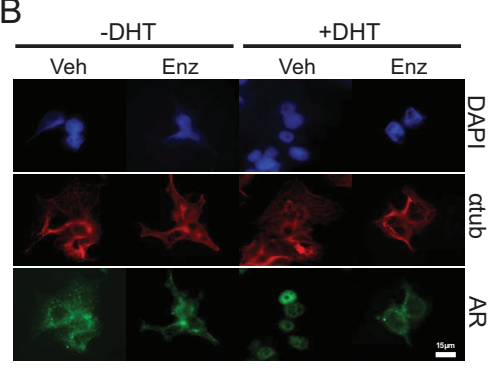

D

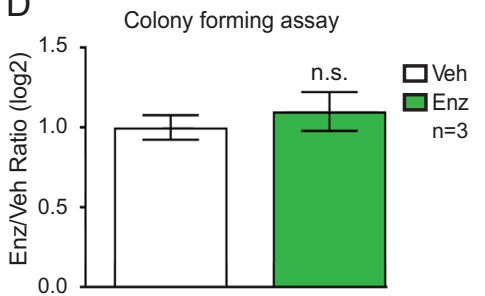

$\mathrm{F}$

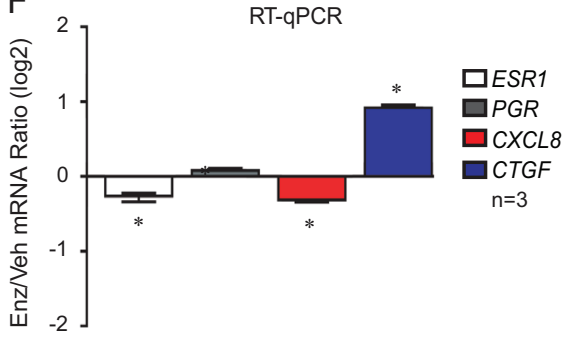

$\mathrm{H}$ LTED

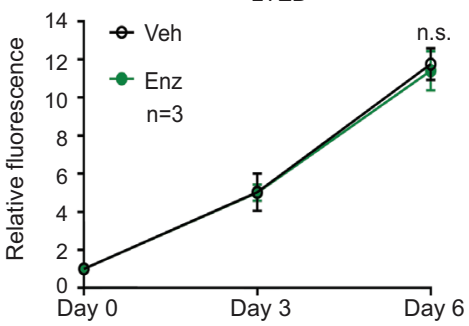

Figure 4

AR pharmacological inhibition does not recapitulate effects of AR knockdown in MCF7 TamR cells. The effect of enzalutamide (Enz) treatment on MCF7 TamR cells in relation to growth and ER signaling was assessed. The effect of $10 \mu \mathrm{M}$ Enz on AR expression and subcellular localization was evaluated using immunoblotting and immunofluorescence. Cells were treated with enzalutamide for $48 \mathrm{~h}$ in the presence or absence of $10 \mathrm{nM}$ DHT prior to harvest for immunoblotting for AR, ER and GAPDH (A) and

immunofluorescence with DAPI (blue) and antibodies against cytoplasmic marker alphatubulin ( $\alpha$ tub; red) and AR (green) (B). Densitometric analysis was performed using Image and data is represented relative to vehicle (Veh)-treated cells in the absence of DHT (RR; relative ratio). (C) Colony-forming assays evaluating the effect of 9-day Veh or Enz treatment on MCF7 TamR cells. (D) Quantification of the colony area coverage using ImageJ and data is presented as the fold change of Enz to Veh treatment. (E) AlamarBlue assessing the effect of $10 \mu \mathrm{M}$ Enz on the viability of MCF7 TamR cells at 3 and 6 days post treatment in the absence or presence of $5 \mu \mathrm{M}$ tamoxifen (Tam). Data is presented as relative to day 0. (F) RT-qPCR was performed to determine the effect of $48 \mathrm{~h} 10 \mu \mathrm{M}$ Enz treatment on ESR1, PGR, CXCL8 and CTGF mRNA levels in MCF7 TamR cells relative to Veh-treated cells. Data is presented as log2 ratio. (G) Cell lysates from MCF7 TamR cells treated with Veh or $10 \mu \mathrm{M}$ Enz for $48 \mathrm{~h}$ were immunoblotted for phospho-Akt at serine 473 (pAKT s473), total Akt, FOXO3a and GAPDH. (H) AlamarBlue assessing the effect of $10 \mu \mathrm{M}$ Enz on the viability of MCF7 LTED cells at 3 and 6 days post treatment. $* P<0.05$, n.s. $=$ not significant, using Student's $t$-test. Error bars $=$ S.E.M. from three biological replicates.

\section{Pharmacological inhibition of AR does not affect in vivo tumor growth of an endocrine-resistant ER+ PDX model}

Lastly, we evaluated the efficacy of enzalutamide on the Gar15-13 PDX in vivo. This model was established from a postmenopausal patient who had tumor recurrence 1 year into adjuvant therapy with the aromatase inhibitor anastrozole (Fig. 5A). Enzalutamide did not affect the basal growth of these tumors relative to vehicle (Fig. 5B), concordant with our in vitro findings with TamR and LTED cells. Moreover, AR was mainly nuclear in this PDX model, unlike the endocrineresistant cells. The proportion of Ki-67-positive cells and the protein levels of cyclin A, markers of proliferation and cells in S-phase respectively, were similar in both treatment arms (Fig. 5C, D and E). Antagonism of canonical AR transcriptional activity with enzalutamide in vivo was evident by reduced mRNA expression of $\mathrm{AR}$ target genes SEC14 Like Lipid Binding 2 (SEC14L2) and FK506 binding protein 5 (FKBP5) (Fig. 5F), and further supported by reduced protein levels of nuclear AR and cellular SEC14L2 (Fig. 5C, G, and Supplementary Fig. 6). In contrast, ER expression was unchanged and remained predominantly nuclear in localization (Fig. 5C) while PR remained negative in enzalutamide-treated tumors (Supplementary Fig. 6). Collectively, these results demonstrate that antagonizing canonical AR activity may not be the optimal treatment option for endocrineresistant breast cancer. 
A

Patient characteristics of endocrine-resistant PDX

\begin{tabular}{|c|c|c|}
\hline Clinical Markers & $\begin{array}{c}\text { ER } \\
\text { PR } \\
\text { HER2 }\end{array}$ & $\begin{array}{c}\text { Pos } \\
\text { Neg } \\
\text { Neg }\end{array}$ \\
\hline Duration of Al Treatment & \multicolumn{2}{|c|}{$\sim$ year } \\
\hline Origin of PDX & \multicolumn{2}{|c|}{ Liver } \\
\hline
\end{tabular}

C

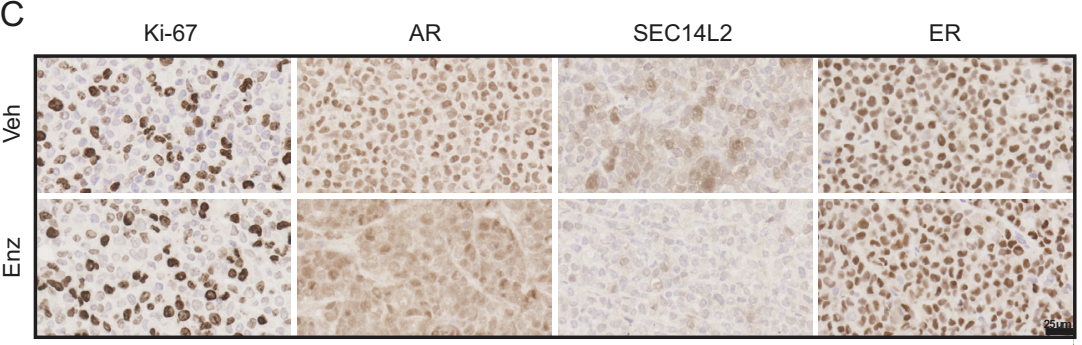

$\mathrm{D}$

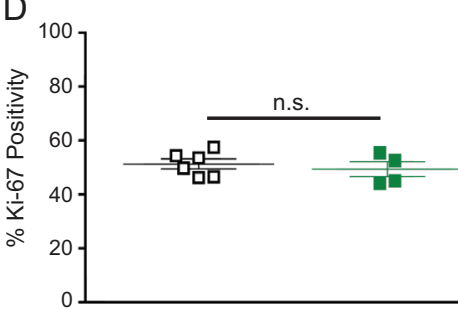

F

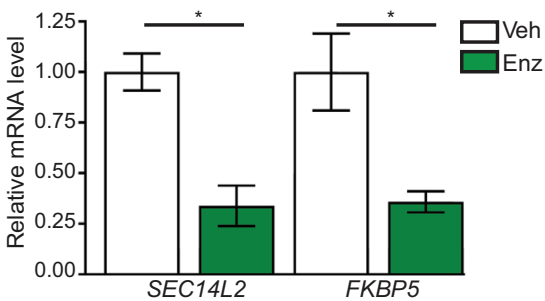

B

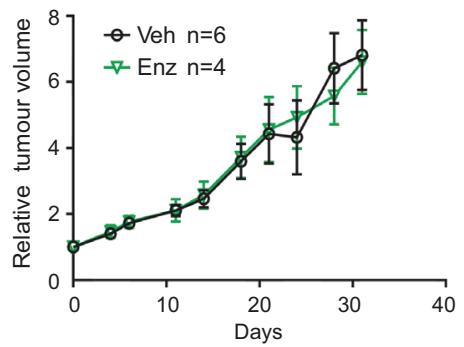

E

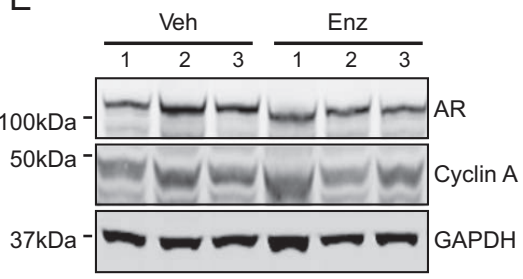

G

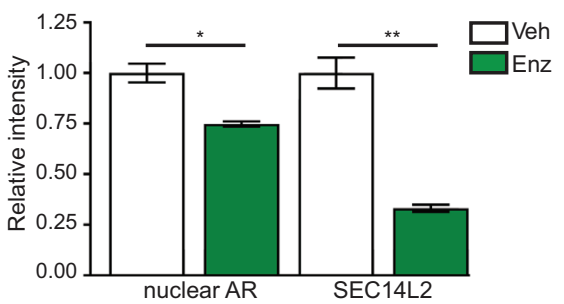

Figure 5

Enzalutamide does not inhibit the growth of an endocrine-resistant PDX. The effect of antagonizing AR using enzalutamide (Enz) on an $E R+A R+$ endocrine-resistant PDX was assessed. (A) This PDX model was established from the liver metastasis of a patient with ER+PR+HER2- breast cancer who relapsed after 1 year of adjuvant aromatase inhibitor treatment. (B) PDX-bearing mice were treated with either vehicle (Veh) or $20 \mathrm{mg} / \mathrm{kg}$ Enz when tumors reached 150 $200 \mathrm{~mm}^{3}$. Tumors were harvested when they reached the ethical endpoint of $1000 \mathrm{~mm}^{3}$ and data is presented as fold change of tumor volumes at harvest from baseline tumor volumes. (C) IHC staining was performed to determine the effect of treatment on Ki-67, AR, SEC14L2 and ER. Representative images at $80 \times$ are presented. Scale bar $=25 \mu \mathrm{m}$ (D) Proliferation index of tumors treated with Veh or Enz were determined. This was based on the quantification of proportion of cells positive for Ki-67 in >1000 cells from at least three random high-magnification fields. (E) Protein lysates extracted from Veh- or Enz-treated tumors were immunoblotted for AR, cyclin A and GAPDH. (F) Intensity of nuclear AR and total SECL14L2 was performed using Image and data is represented as intensity of Enz $(n=6)$ relative to Veh $(n=4)$. (G) RT-qPCR was performed to determine the effect of Enz treatment $(n=3)$ on SECL14L2 and FKBP5 relative to Veh treatment $(n=3) . * P<0.05, * * P<0.01$ and n.s. $=$ not significant using Student's $t$-test. Error bars = S.E.M.

\section{Discussion}

AR has been implicated in the development of endocrine-resistant breast cancer but the mechanistic basis remains unclear. In this study, we investigated the consequences of transient knockdown and pharmacological antagonism of endogenous AR using a combination of endocrine-resistant $\mathrm{ER}+\mathrm{AR}+$ cell line and PDX models. Results from our in vitro siAR experiments to knockdown AR in cell lines support the hypothesis that AR can facilitate endocrine resistance. However, we found that AR is predominantly located in the cytoplasm of endocrine-resistant cells under normal growth conditions, which implicates non-canonical signaling rather than canonical, nuclear AR activity. In support of this, treatment with an AR antagonist, enzalutamide, did not phenocopy the effect of AR (c) 2019 Society for Endocrinology Published by Bioscientifica Ltd. Printed in Great Britain knockdown despite demonstrable inhibitory effects on canonical, ligand-induced AR transactivation events. Likewise, enzalutamide failed to inhibit the in vivo growth of an endocrine-resistant PDX model, although it inhibited AR nuclear localization and transcriptional activity. Non-canonical activity of AR and other steroid hormone receptors, including ER, have been described previously (Bjornstrom \& Sjoberg 2005, Zarif \& Miranti 2016, Leung \& Sadar 2017), but the clinical significance of this type of AR signaling in breast cancer remains unclear. These findings suggest that the role of AR in endocrine-resistant breast cancer is complex and may be modulated by conditions that impinge upon the ability of AR to signal in a non-canonical manner.

The loss of proliferative capacity observed with knockdown of endogenous AR in the endocrine-resistant cell line models supported previous findings that AR 
plays a role in the proliferation of breast cancer cells (De Amicis et al. 2010, Rechoum et al. 2014, Ciupek et al. 2015). However, our data provide further mechanistic insight by revealing that this effect is likely due to the non-canonical signaling activity rather than canonical nuclear activity of AR. AR knockdown also reduced the proliferation of ES MCF7 cells, both in maintenance and estrogen-supplemented media conditions (Yeh et al. 2003, D'Amato et al. 2016) and importantly, these studies provided evidence of functional non-canonical AR activity in breast cancer cells. Yeh et al. (2003) observed that AR-null MCF7 cells had defective MAPK activity that was restored by overexpression of a truncated form of AR lacking the ligand-binding domain. D'Amato et al. (2016) revealed that estrogen induced AR nuclear translocation and binding to non-canonical DNA response elements, whereas androgen recruited AR to canonical DNA response elements. While we observed AR to be predominantly in the cytoplasm of cells, some nuclear protein was evident. Treatment with enzalutamide reduced nuclear AR but had no impact on cell proliferation, suggesting that the limited nuclear AR present in our models was not playing a significant mitogenic role. Hence, our data and that of others support the hypothesis that non-canonical activity of the AR has mitogenic effects on endocrine-sensitive and -resistant forms of MCF7 cells.

In addition to inhibiting the growth of TamR cells, AR knockdown also restored features of classical ER signaling and sensitivity to the anti-proliferative effect of tamoxifen. This effect of AR loss on ER signaling in TamR cells has not been reported previously and appears to be distinct from the effect of AR loss in ES MCF7 cells, which reduced classical activation of ER under estradiol-stimulated conditions (Yeh et al. 2003). This dichotomous effect of AR on ER signaling in an endocrine-sensitive vs -resistant state could be ascribed to the different expression levels of AR or key nuclear co-factors that influence AR and ER function. In ES MCF7 cells, low endogenous levels of AR could facilitate ER activity (Yeh et al. 2003, D'Amato et al. 2016), but the relatively higher levels of AR in TamR cells inhibited classical ER activity in our study. Lanzino et al. (2005) demonstrated that overexpression of AR in MCF7 cells suppressed classical ER signaling via the sequestration of an AR-associated protein of $70 \mathrm{kDa}$ (ARA70), a co-factor of ER and AR. Increased expression of FOXA1 in the TamR cells may also play a role as this transcription factor is known to be important for ER and AR signaling in breast cancer cells (Augello et al. 2011) and FOXA1 regulates ER activity in ES and endocrine-resistant breast cancer (RossInnes et al. 2012).
The increase in classical ER signaling events and restoration of sensitivity to tamoxifen induced by loss of cytoplasmic AR in the TamR cells mirrors the effect observed with inhibition of PI3K/Akt in ES MCF7 cells (Bosch et al. 2015). This suggests a functional link between the non-canonical activity of AR and the PI3K/ Akt signaling pathway in contributing to the acquisition of endocrine resistance. The exact mechanism by which AR influences PI3K/Akt pathway is unknown but a direct interaction between AR and epidermal growth factor receptor (EGFR) has been reported (Ciupek et al. 2015). Hence, it is possible that perturbation of this AR-EGFR interaction impacts on growth factor signaling and the downstream PI3K/Akt pathway (Ciupek et al. 2015).

Although AR knockdown reduced proliferation of endocrine-resistant cells and restored sensitivity to tamoxifen, this was not recapitulated by pharmacological inhibition of AR with enzalutamide. Similarly, enzalutamide did not affect the growth of an estrogen-independent PDX model derived from a patient who progressed on an aromatase inhibitor. This lack of therapeutic efficacy cannot be attributed to insufficient dosing because enzalutamide effectively antagonized canonical AR signaling as evidenced by reduced AR nuclear expression and transcriptional activity. Our results do not concur with a previous study (D'Amato et al. 2016) in which enzalutamide re-sensitized MCF7 TamR cells to tamoxifen in vitro and significantly suppressed growth of TamR xenografts in vivo when given as a monotherapy. Differences in the dose of enzalutamide used could account for these divergent results. Enzalutamide has been reported to suppress growth of AR-negative breast cancer cell lines in vitro when used at $>10 \mu \mathrm{M}$ concentrations (Thakkar et al. 2016), implicating off-target effects of enzalutamide in breast cancer cell lines. In support of this, we demonstrate that enzalutamide significantly reduced the viability of an ER+ AR-null T47D derivative cell line at doses $>10 \mu \mathrm{M}$ (Supplementary Fig. 7). Notably, D'Amato et al. (2016) reported that enzalutamide suppressed colony formation of TamR cells at a minimal dose of $20 \mu \mathrm{M}$. Likewise, the growth-suppressive effect of enzalutamide on TamR xenografts in vivo was achieved with $50 \mathrm{mg} / \mathrm{kg}$, which is greater than the $10-30 \mathrm{mg} / \mathrm{kg}$ doses commonly used in prostate cancer models (Evans et al. 2011, Lin et al. 2013, Moilanen et al. 2015). We used a dose of $20 \mathrm{mg} / \mathrm{kg}$ in our in vivo experiments to minimize the offtarget effects of enzalutamide, and there was demonstrable anti-androgenic effect in tumor cells within our PDX. Collectively, these data strongly support the concept that canonical AR signaling does not promote growth of endocrine-resistant breast cancer. 
Observations from previous AR-targeted clinical studies also support the notion that canonical AR signaling does not promote growth of endocrine-resistant breast cancer and that the use of $\mathrm{AR}$ antagonists is ineffective in the endocrine-resistant setting. Two clinical trials have assessed the efficacy of AR antagonists in breast cancer, and both have reported no clinical benefit from AR inhibition. The first study trialed the first generation AR antagonist flutamide in non-selected patients with metastatic breast cancer (Perrault et al. 1988). The second and more recent study evaluated the efficacy of androgen biosynthesis inhibitor abiraterone acetate in ER+ patients who had progressed on a non-steroidal aromatase inhibitor (O'Shaughnessy et al. 2016), a similar clinical context to the patient from which our PDX model was generated from.

In contrast, multiple clinical studies have reported that the use of AR agonists to activate canonical AR activity in endocrine-resistant breast cancer is associated with tumor suppression and a clinical benefit rate of 38-50\% (Birrell et al. 1995, Boni et al. 2014, Overmoyer et al. 2015, Kono et al. 2016). The agents used to activate AR in these studies include testosterone (Boni et al. 2014), testosterone analog fluoxymesterone (Kono et al. 2016, medroxyprogesterone acetate, which is a synthetic progestin with androgenic activity \{Birrell, 1995 \#1794), and a selective AR modulator that induces a selected spectrum of AR activity (Overmoyer et al. 2015). In agreement, activation of AR with DHT in the MCF7 TamR cells reduced growth of these cells and transient knockdown of AR abolished this DHT-induced growth inhibition, which suggests that the expression and canonical activity of AR is critical for AR agonist-induced growth inhibition (Supplementary Fig. 8).

A caveat of our study is the use of a single endocrineresistant PDX model derived from a liver metastasis. Despite this, our observations are valuable as PDX models are considered the most clinically relevant and resistance to aromatase inhibition, a feature of this model, is frequently fatal. Further investigation using additional PDX models of tamoxifen and AI resistance, as well as models derived from different metastatic deposits, are warranted. While our in vivo data strongly support the concept that canonical, nuclear AR signaling does not promote endocrine-resistant breast cancer, it would be informative to test pharmacological degradation of $\mathrm{AR}$ in vivo to mimic the siRNA-mediated knockdown we performed in endocrine-resistant cells in vitro. Novel AR degraders are in development for the treatment of castrate-resistant prostate cancer \{Salami, 2018 \#2071\} and may help resolve the role of AR in endocrine-resistant breast cancer.
In summary, our study provides evidence that noncanonical AR activity facilitates an endocrine-resistant phenotype in breast cancer, and this activity cannot be inhibited pharmacologically with the AR antagonist enzalutamide. The lack of efficacy associated with the use of enzalutamide in our study has implications for current and future clinical trials that aim to specifically target $\mathrm{AR}$ in endocrine-resistant breast cancer.

\section{Supplementary data}

This is linked to the online version of the paper at https://doi.org/10.1530/ ERC-18-0333.

\section{Declaration of interest}

The authors declare that there is no conflict of interest that could be perceived as prejudicing the impartiality of the research reported.

\section{Funding}

This study was funded by Cancer Australia (ID: 1107170 E L, T E H and W D T), Cancer Institute of NSW (ID: ECF171156 H M), Love Your Sister (E L), National Health and Medical Research Council (ID: 1008349 W D T, ID: 1084416 W D T and T E H, ID: 1093801 K C), Royal Adelaide Hospital Research Foundation (Florey Career Development Fellowship, T E H) and National Breast Cancer Foundation Endowed Chair (E L).

\section{Author contribution statement}

W D T, T E H and E L conceived and designed the project. K C, TE H and $\mathrm{E} L$ planned and designed the experiments. $\mathrm{K} C$ oversaw and performed experiments, and co-wrote the manuscript with $\mathrm{T} E \mathrm{H}$, with critical editing from $W D T$ and $E$ L. H M and N D performed the bioinformatic analyses. N P, R C, A Y and G L-L performed some of the experiments. A S, D S, A P and $C E C$ assisted with interpretation of the results. All authors have read and approved the final manuscript.

\section{Acknowledgements}

The authors would like to thank participating patients who contribute to our PDX biobank and the excellent services provided by the Tissue Culture Facility and Biological Testing Facility at the Garvan Institute of Medical Research. W D Tilley, T E Hickey and E Lim are equal contributing authors.

\section{References}

Aleskandarany MA, Abduljabbar R, Ashankyty I, Elmouna A, Jerjees D, Ali S, Buluwela L, Diez-Rodriguez M, Caldas C, Green AR, et al. 2016 Prognostic significance of androgen receptor expression in invasive breast cancer: transcriptomic and protein expression analysis. Breast Cancer Research and Treatment 159 215-227. (https://doi.org/10.1007/ s10549-016-3934-5)

Ali A, Creevey L, Hao Y, McCartan D, O'Gaora P, Hill A, Young L \& McIlroy M 2015 Prosaposin activates the androgen receptor and potentiates resistance to endocrine treatment in breast cancer. Breast Cancer Research 17 123. (https://doi.org/10.1186/s13058-015-0636-6) 
Augello MA, Hickey TE \& Knudsen KE 2011 FOXA1: master of steroid receptor function in cancer. EMBO Journal 30 3885-3894. (https:// doi.org/10.1038/emboj.2011.340)

Bailey ST, Westerling T \& Brown M 2015 Loss of estrogen-regulated microRNA expression increases HER2 signaling and is prognostic of poor outcome in luminal breast cancer. Cancer Research 75 436-445. (https://doi.org/10.1158/0008-5472.CAN-14-1041)

Birrell SN, Roder DM, Horsfall DJ, Bentel JM \& Tilley WD 1995 Medroxyprogesterone acetate therapy in advanced breast cancer: the predictive value of androgen receptor expression. Journal of Clinical Oncology 13 1572-1577. (https://doi.org/10.1200/ JCO.1995.13.7.1572)

Bjornstrom L \& Sjoberg M 2005 Mechanisms of estrogen receptor signaling: convergence of genomic and nongenomic actions on target genes. Molecular Endocrinology 19 833-842. (https://doi. org/10.1210/me.2004-0486)

Boni C, Pagano M, Panebianco M, Bologna A, Sierra NM, Gnoni R, Formisano D \& Bisagni G 2014 Therapeutic activity of testoterone in metastatic breast cancer. Anticancer Research 34 1287-1290.

Bosch A, Li Z, Bergamaschi A, Ellis H, Toska E, Prat A, Tao JJ, Spratt DE, Viola-Villegas NT, Castel P, et al. 2015 PI3K inhibition results in enhanced estrogen receptor function and dependence in hormone receptor-positive breast cancer. Science Translational Medicine $\mathbf{7}$ 283ra51. (https://doi.org/10.1126/scitranslmed.aaa4442)

Chia KM, Liu J, Francis GD \& Naderi A 2011 A feedback loop between androgen receptor and ERK signaling in estrogen receptor-negative breast cancer. Neoplasia 13 154-166. (https://doi.org/10.1593/ neo.101324)

Chia K, O'Brien M, Brown M \& Lim E 2015 Targeting the androgen receptor in breast cancer. Current Oncology Reports 17 4. (https://doi. org/10.1007/s11912-014-0427-8)

Chung WM, Chang WC, Chen L, Lin TY, Chen LC, Hung YC \& Ma WL 2014 Ligand-independent androgen receptors promote ovarian teratocarcinoma cell growth by stimulating self-renewal of cancer stem/progenitor cells. Stem Cell Research 13 24-35. (https://doi. org/10.1016/j.scr.2014.04.003)

Ciupek A, Rechoum Y, Gu G, Gelsomino L, Beyer AR, Brusco L, Covington KR, Tsimelzon A \& Fuqua SA 2015 Androgen receptor promotes tamoxifen agonist activity by activation of EGFR in ERalpha-positive breast cancer. Breast Cancer Research and Treatment 154 225-237. (https://doi.org/10.1007/s10549-015-3609-7)

D'Amato NC, Gordon MA, Babbs B, Spoelstra NS, Carson Butterfield KT, Torkko KC, Phan VT, Barton VN, Rogers TJ, Sartorius CA, et al. 2016 Cooperative dynamics of AR and ER activity in breast cancer. Molecular Cancer Research 14 1054-1067. (https://doi. org/10.1158/1541-7786.MCR-16-0167)

De Amicis F, Thirugnansampanthan J, Cui Y, Selever J, Beyer A, Parra I, Weigel NL, Herynk MH, Tsimelzon A, Lewis MT, et al. 2010 Androgen receptor overexpression induces tamoxifen resistance in human breast cancer cells. Breast Cancer Research and Treatment 121 1-11. (https://doi.org/10.1007/s10549-009-0436-8)

Dowsett M, Nielsen TO, A'Hern R, Bartlett J, Coombes RC, Cuzick J, Ellis M, Henry NL, Hugh JC, Lively T, et al. 2011 Assessment of Ki67 in breast cancer: recommendations from the International Ki67 in Breast Cancer working group. Journal of the National Cancer Institute 103 1656-1664. (https://doi.org/10.1093/jnci/djr393)

Early Breast Cancer Trialists' Collaborative Group (EBCTCG) 2005 Effects of chemotherapy and hormonal therapy for early breast cancer on recurrence and 15-year survival: an overview of the randomised trials. Lancet 365 1687-1717. (https://doi.org/10.1016/S01406736(05)66544-0)

Evans MJ, Smith-Jones PM, Wongvipat J, Navarro V, Kim S, Bander NH, Larson SM \& Sawyers CL 2011 Noninvasive measurement of androgen receptor signaling with a positron-emitting radiopharmaceutical that targets prostate-specific membrane antigen. PNAS 108 9578-9582. (https://doi.org/10.1073/pnas.1106383108)
Fu X, Jeselsohn R, Pereira R, Hollingsworth EF, Creighton CJ, Li F, Shea M, Nardone A, De Angelis C, Heiser LM, et al. 2016 FOXA1 overexpression mediates endocrine resistance by altering the ER transcriptome and IL-8 expression in ER-positive breast cancer. PNAS 113 E6600-E6609. (https://doi.org/10.1073/pnas.1612835113)

Fujii R, Hanamura T, Suzuki T, Gohno T, Shibahara Y, Niwa T, Yamaguchi Y, Ohnuki K, Kakugawa Y, Hirakawa H, et al. 2014 Increased androgen receptor activity and cell proliferation in aromatase inhibitor-resistant breast carcinoma. Journal of Steroid Biochemistry and Molecular Biology 144 (Pt B) 513-522. (https://doi. org/10.1016/j.jsbmb.2014.08.019)

Gautier L, Cope L, Bolstad BM \& Irizarry RA 2004 affy - analysis of Affymetrix GeneChip data at the probe level. Bioinformatics 20 307-315. (https://doi.org/10.1093/bioinformatics/btg405)

Gentleman RC, Carey VJ, Bates DM, Bolstad B, Dettling M, Dudoit S, Ellis B, Gautier L, Ge Y, Gentry J, et al. 2004 Bioconductor: open software development for computational biology and bioinformatics. Genome Biology 5 R80. (https://doi.org/10.1186/gb-2004-5-10-r80)

Greeve MA, Allan RK, Harvey JM \& Bentel JM 2004 Inhibition of MCF-7 breast cancer cell proliferation by 5alpha-dihydrotestosterone; a role for p21(Cip1/Waf1). Journal of Molecular Endocrinology 32 793-810. (https://doi.org/10.1677/jme.0.0320793)

Guo S \& Sonenshein GE 2004 Forkhead box transcription factor FOXO3a regulates estrogen receptor alpha expression and is repressed by the Her-2/neu/phosphatidylinositol 3-kinase/Akt signaling pathway. Molecular and Cellular Biology 24 8681-8690. (https://doi.org/10.1128/MCB.24.19.8681-8690.2004)

Guzman C, Bagga M, Kaur A, Westermarck J \& Abankwa D 2014 ColonyArea: an ImageJ plugin to automatically quantify colony formation in clonogenic assays. PLOS ONE 9 e92444. (https://doi. org/10.1371/journal.pone.0092444)

Hickey TE, Robinson JL, Carroll JS \& Tilley WD 2012 Minireview: the androgen receptor in breast tissues: growth inhibitor, tumor suppressor, oncogene? Molecular Endocrinology 26 1252-1267. (https://doi.org/10.1210/me.2012-1107)

Holmes KA, Brown GD \& Carroll JS 2016 Chromatin immunoprecipitation-Sequencing (ChIP-seq) for Mapping of estrogen receptor-chromatin Interactions in Breast Cancer. Methods in Molecular Biology 1366 79-98. (https://doi.org/10.1007/978-14939-3127-9_8)

Hurtado A, Holmes KA, Ross-Innes CS, Schmidt D \& Carroll JS 2011 FOXA1 is a key determinant of estrogen receptor function and endocrine response. Nature Genetics $\mathbf{4 3}$ 27-33. (https://doi. org/10.1038/ng.730)

Irizarry RA, Hobbs B, Collin F, Beazer-Barclay YD, Antonellis KJ, Scherf U \& Speed TP 2003 Exploration, normalization, and summaries of high density oligonucleotide array probe level data. Biostatistics $\mathbf{4}$ 249-264. (https://doi.org/10.1093/biostatistics/4.2.249)

Jeselsohn R, Cornwell M, Pun M, Buchwalter G, Nguyen M, Bango C, Huang Y, Kuang Y, Paweletz C, Fu X, et al. 2017 Embryonic transcription factor SOX9 drives breast cancer endocrine resistance. PNAS 114 E4482-E4491. (https://doi.org/10.1073/ pnas.1620993114)

Kono M, Fujii T, Lyons GR, Huo L, Bassett R, Gong Y, Karuturi MS, Tripathy D \& Ueno NT 2016 Impact of androgen receptor expression in fluoxymesterone-treated estrogen receptor-positive metastatic breast cancer refractory to contemporary hormonal therapy. Breast Cancer Research and Treatment 160 101-109. (https://doi.org/10.1007/ s10549-016-3986-6)

Lanzino M, De Amicis F, McPhaul MJ, Marsico S, Panno ML \& Ando S 2005 Endogenous coactivator ARA70 interacts with estrogen receptor alpha (ERalpha) and modulates the functional ERalpha/androgen receptor interplay in MCF-7 cells. Journal of Biological Chemistry $\mathbf{2 8 0}$ 20421-20430. (https://doi.org/10.1074/jbc.M413576200)

Lapointe J, Fournier A, Richard V \& Labrie C 1999 Androgens downregulate bcl-2 protooncogene expression in ZR-75-1 human breast (c) 2019 Society for Endocrinology Published by Bioscientifica Ltd. Printed in Great Britain 
cancer cells. Endocrinology 140 416-421. (https://doi.org/10.1210/ endo.140.1.6410)

Lehmann BD, Bauer JA, Chen X, Sanders ME, Chakravarthy AB, Shyr Y \& Pietenpol JA 2011 Identification of human triple-negative breast cancer subtypes and preclinical models for selection of targeted therapies. Journal of Clinical Investigation 121 2750-2767. (https:// doi.org/10.1172/JCI45014)

Leung JK \& Sadar MD 2017 Non-genomic actions of the androgen receptor in prostate cancer. Frontiers in Endocrinology $\mathbf{8} 2$.

Lin TH, Lee SO, Niu Y, Xu D, Liang L, Li L, Yeh SD, Fujimoto N, Yeh S \& Chang C 2013 Differential androgen deprivation therapies with anti-androgens Casodex/bicalutamide or MDV3100/Enzalutamide versus anti-androgen receptor ASC-J9(R) lead to promotion versus suppression of prostate cancer metastasis. Journal of Biological Chemistry 288 19359-19369. (https://doi.org/10.1074/jbc. M113.477216)

Macedo LF, Guo Z, Tilghman SL, Sabnis GJ, Qiu Y \& Brodie A 2006 Role of androgens on MCF-7 breast cancer cell growth and on the inhibitory effect of letrozole. Cancer Research 66 7775-7782. (https:// doi.org/10.1158/0008-5472.CAN-05-3984)

Micello D, Marando A, Sahnane N, Riva C, Capella C \& Sessa F 2010 Androgen receptor is frequently expressed in HER2-positive, ER/ PR-negative breast cancers. Virchows Archiv 457 467-476. (https:// doi.org/10.1007/s00428-010-0964-y)

Moilanen AM, Riikonen R, Oksala R, Ravanti L, Aho E, Wohlfahrt G, Nykanen PS, Tormakangas OP, Palvimo JJ \& Kallio PJ 2015 Discovery of ODM-201, a new-generation androgen receptor inhibitor targeting resistance mechanisms to androgen signaling-directed prostate cancer therapies. Scientific Reports 5 12007. (https://doi.org/10.1038/ srep12007)

Murphy LC, Niu Y, Snell L \& Watson P 2004 Phospho-serine-118 estrogen receptor-alpha expression is associated with better disease outcome in women treated with tamoxifen. Clinical Cancer Research 10 5902-5906. (https://doi.org/10.1158/1078-0432.CCR-04-0191)

Ni M, Chen Y, Lim E, Wimberly H, Bailey ST, Imai Y, Rimm DL, Liu XS \& Brown M 2011 Targeting androgen receptor in estrogen receptornegative breast cancer. Cancer Cell 20 119-131. (https://doi. org/10.1016/j.ccr.2011.05.026)

Niemeier LA, Dabbs DJ, Beriwal S, Striebel JM \& Bhargava R 2010 Androgen receptor in breast cancer: expression in estrogen receptorpositive tumors and in estrogen receptor-negative tumors with apocrine differentiation. Modern Pathology 23 205-212. (https://doi. org/10.1038/modpathol.2009.159)

Oakes SR, Vaillant F, Lim E, Lee L, Breslin K, Feleppa F, Deb S, Ritchie ME, Takano E, Ward T, et al. 2012 Sensitization of BCL-2expressing breast tumors to chemotherapy by the BH3 mimetic ABT737. PNAS 109 2766-2771. (https://doi.org/10.1073/ pnas.1104778108)

O'Shaughnessy J, Campone M, Brain E, Neven P, Hayes D, Bondarenko I, Griffin TW, Martin J, De Porre P, Kheoh T, et al. 2016 Abiraterone acetate, exemestane or the combination in postmenopausal patients with estrogen receptor-positive metastatic breast cancer. Annals of Oncology 27 106-113. (https://doi. org/10.1093/annonc/mdv487)

Overmoyer B, Sanz-Altimira P, Partridge AH, Extermann M, Liu J, Winer E, Lin N, Hassett M, Parker L, Taylor R, et al. 2015 Abstract P1-13-04: Enobosarm for the treatment of metastatic, estrogen and androgen receptor positive, breast cancer. Final results of the primary endpoint and current progression free survival. Cancer Research 75 P1-13-04-P11-13-04. (https://doi.org/10.1158/1538-7445. SABCS14-P1-13-04)
Perrault DJ, Logan DM, Stewart DJ, Bramwell VH, Paterson AH \& Eisenhauer EA 1988 Phase II study of flutamide in patients with metastatic breast cancer. A National Cancer Institute of Canada Clinical Trials Group study. A National Cancer Institute of Canada Clinical Trials Group Study. Investigational New Drugs 6 207-210.

Peters AA, Buchanan G, Ricciardelli C, Bianco-Miotto T, Centenera MM, Harris JM, Jindal S, Segara D, Jia L, Moore NL, et al. 2009 Androgen receptor inhibits estrogen receptor-alpha activity and is prognostic in breast cancer. Cancer Research 69 6131-6140. (https://doi. org/10.1158/0008-5472.CAN-09-0452)

Rechoum Y, Rovito D, Iacopetta D, Barone I, Ando S, Weigel NL, O'Malley BW, Brown PH \& Fuqua SA 2014 AR collaborates with ERalpha in aromatase inhibitor-resistant breast cancer. Breast Cancer Research and Treatment 147 473-485. (https://doi.org/10.1007/ s10549-014-3082-8)

Ricciardelli C, Bianco-Miotto T, Jindal S, Butler LM, Leung S, McNeil CM, O'Toole SA, Ebrahimie E, Millar EKA, Sakko AJ, et al. 2018 The magnitude of androgen receptor positivity in breast cancer is critical for reliable prediction of disease outcome. Clinical Cancer Research 24 2328-2341. (https://doi.org/10.1158/1078-0432.CCR-171199)

Ritchie ME, Phipson B, Wu D, Hu Y, Law CW, Shi W \& Smyth GK 2015 Limma powers differential expression analyses for RNA-sequencing and microarray studies. Nucleic Acids Research 43 e47. (https://doi. org/10.1093/nar/gkv007)

Robinson JL, Macarthur S, Ross-Innes CS, Tilley WD, Neal DE, Mills IG \& Carroll JS 2011 Androgen receptor driven transcription in molecular apocrine breast cancer is mediated by FoxA1. EMBO Journal 30 3019-3027. (https://doi.org/10.1038/emboj.2011.216)

Ross-Innes CS, Stark R, Teschendorff AE, Holmes KA, Ali HR, Dunning MJ, Brown GD, Gojis O, Ellis IO, Green AR, et al. 2012 Differential oestrogen receptor binding is associated with clinical outcome in breast cancer. Nature $\mathbf{4 8 1}$ 389-393. (https://doi. org/10.1038/nature10730)

Subramanian A, Tamayo P, Mootha VK, Mukherjee S, Ebert BL, Gillette MA, Paulovich A, Pomeroy SL, Golub TR, Lander ES, et al. 2005 Gene set enrichment analysis: a knowledge-based approach for interpreting genome-wide expression profiles. PNAS 102 15545-15550. (https://doi.org/10.1073/pnas.0506580102)

Thakkar A, Wang B, Picon-Ruiz M, Buchwald P \& Ince TA 2016 Vitamin $\mathrm{D}$ and androgen receptor-targeted therapy for triple-negative breast cancer. Breast Cancer Research and Treatment 157 77-90. (https://doi. org/10.1007/s10549-016-3807-y)

Tran C, Ouk S, Clegg NJ, Chen Y, Watson PA, Arora V, Wongvipat J, Smith-Jones PM, Yoo D, Kwon A, et al. 2009 Development of a second-generation antiandrogen for treatment of advanced prostate cancer. Science 324 787-790. (https://doi.org/10.1126/ science.1168175

Wang Y, Romigh T, He X, Tan MH, Orloff MS, Silverman RH, Heston WD \& Eng C 2011 Differential regulation of PTEN expression by androgen receptor in prostate and breast cancers. Oncogene 30 4327-4338. (https://doi.org/10.1038/onc.2011.144)

Yeh S, Hu YC, Wang PH, Xie C, Xu Q, Tsai MY, Dong Z, Wang RS, Lee TH \& Chang C 2003 Abnormal mammary gland development and growth retardation in female mice and MCF7 breast cancer cells lacking androgen receptor. Journal of Experimental Medicine 198 1899-1908. (https://doi.org/10.1084/jem.20031233)

Zarif JC \& Miranti CK 2016 The importance of non-nuclear AR signaling in prostate cancer progression and therapeutic resistance. Cellular Signalling 28 348-356. (https://doi.org/10.1016/j. cellsig.2016.01.013)

Received in final form 28 October 2018

Accepted 27 November 2018 https://erc.bioscientifica.com

https://doi.org/10.1530/ERC-18-0333 (c) 2019 Society for Endocrinology Published by Bioscientifica Ltd. Printed in Great Britain 